\title{
PENGARUH PELAYANAN DAN KOMUNIKASI TERHADAP KEPUTUSAN KONSUMEN MENGAMBIL KREDIT SEPEDA MOTOR PADA PT. FEDERAL INTERNATIONAL FINANCE (FIF) LANGGA PAYUNG
}

\author{
Siti Lam'ah Nasution \\ Dosen Tetap Sekolah Tinggi Ilmu Ekonomi Labuhanbatu, Sumatera Utara
}

\begin{abstract}
ABSTRAK
Tujuan dari penelitian ini adalah untuk mengetahui pengaruh pelayanan dan komunikasi terhadap keputusan konsumen mengambil kredit sepeda motor pada PT. Federal International Finance (FIF) Langga Payung. Sampel penelitian ini sebanyak92orang yang diambil denganmenggunakan teknik accidental sampling. Hasil penelitian menunjukkan bahwa pelayanan dan komunikasi secara bersama-sama berpengaruh positif dan signifikan terhadap keputusan konsumen dalam pengambilan kredit sepeda motor pada PT. FIF Langga Payung. Pelayanan lebih dominan berpengaruh terhadap keputusan konsumen dalam pengambilan kredit sepeda motor pada PT. FIF Langga Payung. Berdasarkan hasil uji determinasi diketahui bahwa keputusan konsumen dalam pengambilan kredit sepeda motor pada PT. FIF Langga Payungmampu dijelaskan oleh pelayanan dan komunikasi sebesar $63,1 \%$, sedangkan sisanya 36,9\% dijelaskan oleh faktor lain yang tidak dibahas dalam penelitian ini.
\end{abstract}

\section{Kata kunci : Pelayanan, Komunikasi, Keputusan konsumen.}

\section{PENDAHULUAN}

PT. Federal International Finance (FIF) adalah salah satu perusahaan pembiayaan sepeda motor di Indonesia yang memberikan jasa pembiayaan pemilikan sepeda motor kepada konsumen secara kredit. PT. Federal International Finance (FIF) didirikan tahun 1982 dengan ambisi menjadi perusahaan pembiayaan berkelas dunia dan bergerak terutama di bidang pembiayaan otomotif. Dalam pelaksanaanya PT. Federal International Finance (FIF) adalah perusahaan pembiayaansepeda motorkhusunya Honda. Pemberian kredit yang dilakukan PT. Federal International Finance (FIF) selain melayani pemberian kredit sepeda motor perorangan juga memberikan kredit secara berkelompok baik untuk perusahaan ataupun untuk instansi Pemerintah.

PT. Federal International Finance (FIF) merupakan perusahaan yang telah lama eksis dan mempunyai pangsa pasar yang sangat besar di dalam negeri. Sebagai perusahaan yang telah lama eksis, PT. Federal International Finance (FIF) berupaya untuk terus mengembangkan jaringan usaha dengan membuka cabang, kantor perwakilan, titik pelayanan, kios dan dealer outlet setiap tahun. Sampai saat ini, Perusahaan telah memiliki 73 kantor layanan di 52 kota di seluruh wilayah Indonesia. 
Dengan adanya fenomena berkembangnya minat beli masyarakat terhadap sepeda motor dan perkembangan perusahaan pembiayaan sepeda motor di Indonesia tentunya menimbulkan menjadi tantangan bagi PT. Federal International Finance (FIF) untuk memenangkan persaingan. Dalam menarik minat konsumen untuk melakukan pembelian sepeda motor secara kredit, perusahaan pembiayaan melakukan strategi-strategi untuk menarik minat konsumen tersebut, tidak terkecuali dengan PT. Federal International Finance (FJF) I Intık mempertahankan agar perusahaan tetap eksis dan berkembang, PT. Federal Internation $\quad$ IF) melakukan beberapa strategi dalam meningkatkan jumlah konsumen. Salah satu

strategi yang dilakukan PT. Federal International Finance (FIF) untuk tetap bertahan dalam persaingan dengan perusahaan pembiayaan sepeda motor. Untuk dapat menarik simpati pelanggan, maka yang pertama harus diperhatikan adalah pelayanan. Perusahaanpembiayaan seperti FIF sebagai salah satu perusahaan dalam sektor jasa layanan keuangan non bank, kinerjanya akansangat bergantung pada baik atau buruknya layanan secara keseluruhan kepadapara pelanggan. Makin baik layanan dari suatu perusahaan, maka akan semakin relatiflebih mudah untuk mendapatkan kepercayaan dari pelanggan untuk menggunakan jasa pembiayaan kredit sepeda motor tersebut.

Disamping itu, komunikasi pemasaran yang efektif harus dijalankan perusahaan agar penjualan dapat maksimal. Komunikasi merupakan proses pemindahan pengertian dalam bentuk gagasan atau komunikasi dari seseorang ke orang lain. Perpindahan pengertian tersebut melibatkan lebih dari sekedar kata-kata yang di gunakan dalam percakapan, tetapi juga ekspresi wajah, intonasi, titik putus vokal dan sebagainya. Dan perpindahan yang efektif memerlukan tidak hanya transmisi data, tetapi bahwa seseorang mengirimkan berita dan menerimanya sangat tergantung pada ketrampilan-ketrampilan tertentu (membaca, menulis, mendengar, berbicara, dan lain-lain)untuk membuat sukses pertukaran informasi.

Komunikasi merupakan suatu proses penyampaian atau pertukaran informasi antar individu melalui suatu sistem yang (lazim), baik dengan simbol-simbol, sinyal-sinyal maupun perilaku atau tindakan. Jadi dalam komunikasi itu terdapat di dalamnya suatu proses, terdapat simbolsimbol dan simbol-simbol itu mengandung arti. Arti atau makna simbol disini tentu saja tergantung pada pemahaman dan persepsi komunikan sehingga ada umpan balik (feedback) bagi komunikan setelah mendapatkan pesan. Oleh karena itu, komunikasi akan efektif dan tujuan komunikasi akan tercapai, apabila masing-masing pelaku yang terlibat di dalamnya mempunyai persepsi yang sam terhadap simbol.

Dalam komunikasi pemasaran, informasi yang disampaikan adalah semua hal tentang produk yang dijual, meliputi : harga, bentuk, kualitas, dan keunggulan dengan produk lain, yang tujuannya adalah untuk mempengaruhi pelanggan agar mau membeli atau mengkonsumsi produk tersebut. Komunikasi yang dilakukan dalam pemasaran kredit pembiayaan umumnya menyangkut suku bunga yang diberikan, nilai angsuran, periode angsuran, subsidi atau 
potongan, serta informasi yang menyangkut ketentuan dan sanksi dalam perjanjian kredit pembiayaan.

\section{TINJAUAN PUSTAKA}

Menurut Kotler (2009:83), pelayanan iap tindakan atau kegiatanyang dapat ditawarkan oleh suatu pihak kepada pihin ıun, yuns pada dasarnyatidak berwujud dan tidak mengakibatkan kepemilikan apapun.

Menurut Purwanto (2006:20) Komunikasi adalah suatu proses komunikasi yang menggunakan media yaitu bahasa atau simbol-simbol yang biasa digunakan untuk mentransfer pesan-pesan dari pemberi pesan ke penerima pesan melalui proses komunikasi agar diperoleh suatu hasil yang sangat berarti bagi suatu organisasi. Apabila cara menyampaikan pesan dan mengembangkan pesan tidak terdapat masalah-masalah dan si penerima pesan juga dapat menerima pesan dan menafsirkan pesan tersebut maka dengan komunikasi yang efektif ini prestasi kerja karyawan akan meningkat karena karyawan telah mengerti pesan yang disampaikan kepadanya.

Pemahaman mengenai perilaku konsumen ini meliputi bagaimana individu, kelompok dan organisasi, memilih, membeli, menggunakan dan tidak menggunakan barang dan jasa. Tidaklah mudah dalam memahami perilaku konsumen, karena konsumen memutuskan pembelian tertentu yang berbeda setiap hari, dan sangat bervariasi dalam usia, pendapatan, tingkat pendidikan, dan selera. Setiadi (2010:332) menyatakan bahwa inti dari pengambilan keputusan konsumen (cunsumer decision making) adalah proses pengintegrasian yangmengombinasikan pengetahuan untuk mengevaluasi dua atau lebih perilaku alternatif, dan memilih salah satu diantaranya. Pemasar juga perlu mengetahui apa saja yang menjadi bahan pertimbangan orang dalam keputusan pembelian dan peran apa yang dimainkan masingmasing orang.

\section{METODE}

\section{Populasi dan Sampel}

Populasi dalam penelitian ini adalah konsumen yang mengambil kredit sepeda motor di FIF Langga Payung pada tahun 2015 yang berjumlah 1.218 orang.

Ukuransampel ditentukan dengan menggunakan rumus Slovin (Umar, 2006:78) yaitutehnik pengambilan sampel dimana peneliti menggunakan sampel dari populasidengan rumus : 
1218

$=$

$\left(1+1218(0,1)^{2}\right)$

Teknik pengambilan sampel menggunakan metode Accidental sampling yaitu teknik pengambilan sampel dapat dilakukan kepada siapa saja yang secara kebetulan ditemui dan cocok untuk dijadikan sampel, maka orang tersebut dapat digunakan dengan sebagai sampel.

\section{G. Metode Analisis Data}

1. Analisis Deskriptif

Metode analisis deskriptif merupakan cara merumuskan dan menafsirkan data yang ada sehingga memberikan gambaran yang jelas melalui pengumpulan, penyusunan, dan penganalisisan data sehingga dapat diketahui gambaran data yang sedang diteliti. Data diperoleh dari data primer berupa kuesioner yang telah diisi oleh sejumlah responden penelitian.

\section{Analisis Statistik}

\section{a. Analisis Regresi Linier Berganda}

Metode analisis regresi linier berganda digunakan untuk mengetahui berapa besar pengaruh variabel independen (brand image, harga, dan promosi) terhadap variabel dependen (keputusan pembelian). Data diolah secara statistik untuk keperluan analisis dan pengujian hipotesis dengan menggunakan alat bantu program SPSS 20.0 for windows.

Adapun bentuk umum persamaan regresi yang digunakan adalah sebagai berikut:

$=\mathbf{a}+\mathbf{b}_{1} \mathbf{X}_{1}+\mathbf{b}_{2} \mathbf{X}_{2}+e$ Keterangan :

$\mathrm{Y}=$ Keputusan konsumen

$\mathrm{a}=$ Konstanta

$\mathrm{b}_{1}, \mathrm{~b}_{2}, \mathrm{~b}_{3}=$ Koefisien regresi

$\mathrm{X}_{1}=$ Pelayanan

$\mathrm{X}_{2}=$ Komunikasi

$e=$ Standar error

\section{b.Pengujian Hipotesis}

Suatu perhitungan statistik disebut signifikan secara statistik apabila nilai uji statistik berada dalam daerah kritis (daerah dimana Ho ditolak). Sebaliknya, disebut tidak signifikan bila nilai uji statistik berada dalam daerah dimana Ho diterima. 


\section{1) Uji Signifikansi Parsial (Uji t)}

Uji t menentukan seberapa besar pengaruh variabel independen (X) secara parsial terhadap variabel dependen (Y). Kriteria pengujian adalah :

$\mathrm{H}_{0}: \mathrm{b}_{1}=\mathrm{b}_{2}=\mathrm{b}_{3}=0$, artinya secara parsial tidak terdapat pengaruh yang positif dan signifikan antara variabel independen $\left(\mathrm{X}_{1}\right.$ dan $\left.\mathrm{X}_{2}\right)$ yaitu pelayanan dan komunikasi terhadap variabel dependen (Y) yaitu keputusan konsumen dalam pengambilan kredit sepeda motor.

$\mathrm{Ha}: \mathrm{b}_{1} \neq \mathrm{b}_{2} \neq \mathrm{b}_{3} \neq 0$, artinya secara parsial terdapat pengaruh yang positif dan signifikan antara variabel independen $\left(\mathrm{X}_{1}\right.$ dan $\left.\mathrm{X}_{2}\right)$ yaitu pelayanan dan

komunikasiterhadap variabel dependen (Y) yaitu keputusan konsumen dalam pengambilan kredit sepeda motor.

Kriteria pengambilan keputusan :

Ho diterima jika thitung $<$ tabel pada $\alpha=5 \%$.

Ha ditolak jika thitung > tabel pada $\alpha=5 \%$.

\section{Uji Signifikansi Simultan (Uji-F)}

Uji-F pada dasarnya menunjukkan apakah semua variabel independen yang dimasukkan dalam model mempunyai pengaruh secara bersama-sama terhadap variabel dependen. Kriteria pengujian adalah :

$\mathrm{H}_{0}: \mathrm{b}_{1}=\mathrm{b}_{2}=\mathrm{b}_{3}=0$, artinya secara bersama-sama tidak terdapat pengaruh yang positif dan signifikan antara variabel independen $\left(\mathrm{X}_{1}\right.$ dan $\left.\mathrm{X}_{2}\right)$ yaitu pelayanan dan komunikasi terhadap variabel dependen $(\mathrm{Y})$ yaitu keputusan konsumen dalam pengambilan kredit sepeda motor.

$\mathrm{Ha}: \mathrm{b}_{1} \neq \mathrm{b}_{2} \neq \mathrm{b}_{3} \neq 0$, artinya secara bersama-sama terdapat pengaruh yang positif dan signifikan antara variabel independen $\left(\mathrm{X}_{1}\right.$ dan $\left.\mathrm{X}_{2}\right)$ yaitu pelayanan dan komunikasi terhadap variabel dependen (Y) yaitu keputusan konsumen dalam pengambilan kredit sepeda motor.

Ho diterima jika Fhitung $<$ Ftabel pada $\alpha=5 \%$.

Ha ditolak jika Fhitung $>$ Ftabel pada $\alpha=5 \%$.

Koefisien Determinasi $\left(R^{2}\right)$

Koefisien determinasi $\left(R^{2}\right)$ pada intinya mengukur seberapa besar kemampuan model dalam menerangkan variabel dependen. Jika $R^{2}$ semakin besar (mendekati satu), maka dapat 
dikatakan bahwa hubungan variabel independen $\left(\mathrm{X}_{1}, \mathrm{X}_{2}\right)$ adalah besar terhadap variabel dependen (Y). Hal ini berarti model yang digunakan semakin kuat untuk menerangkan hubungan variabel independen yang diteliti terhadap variabel dependen. Sebaliknya, jika $R^{2}$ semakin kecil (mendekati nol) maka dapat dikatakan bahwa hubungan variabel independen $\left(\mathrm{X}_{1}, \mathrm{X}_{2}\right.$, dan $\left.\mathrm{X}_{3}\right)$ terhadap variabel dependen (Y) semakin kecil. Hal ini berarti model yang digunakan tidak kuat. Secara umum dapat dikatakan besarnya koefisien determinasi berganda $\left(R^{2}\right)$ berada diantara 0 dan 1 atau $0 \leq R^{2} \leq 1$.

\section{HASIL DAN PEMABAHASAN}

\section{Hasil Analisis Regresi Linear Berganda}

Dalam melakukan analisis regresi linear berganda digunakan bantuan program aplikasi SPSS 20.0. Hasil pengolahan data ditampilkan seperti pada Tabel berikut :

\section{Tabel 1}

\section{Hasil Regresi Berganda}

Coefficients $^{\mathrm{a}}$

a. Dependent Variable: Keputusan konsumen

\begin{tabular}{|c|c|c|c|c|c|c|}
\hline \multirow{2}{*}{\multicolumn{2}{|c|}{ Model }} & \multicolumn{2}{|c|}{ Unstandardized Coefficients } & \multirow{2}{*}{\begin{tabular}{|l|l}
$\begin{array}{l}\text { Standardized } \\
\text { Coefficients }\end{array}$ \\
Beta
\end{tabular}} & $t$ & \multirow[t]{2}{*}{ Sig. } \\
\hline & & $B$ & Std. Error & & & \\
\hline \multirow{3}{*}{1} & (Constant) & $\beta, 784$ & 1,271 & & 2,977 &, 004 \\
\hline & Pelayanan &, 487 & 065 & 537 & 7,467 &, 000 \\
\hline & Komunikasi & 328 &, 060 & 393 & 5,463 &, 000 \\
\hline
\end{tabular}

Berdasarkan Tabel 1 pada kolom B Unstandardized Coefficientsmaka dapat dibentuk persamaan sebagai berikut :

$Y=3,784+0,487 X_{1}+0,328 X_{2}$

Persamaan diatas dapat diinterpretasikan sebagai berikut :

Konstanta (a) = 3,784, artinya bahwa jika pelayanan dan komunikasi tidak ada (bernilai nol), maka keputusan konsumen dalam pengambilan kredit sepeda motor sebesar 3,784.

Koefisien $b_{1}=0,487$, artinya bahwa jika variabel pelayanan $\left(\mathrm{X}_{1}\right)$ naik satu satuan dan variabel lainnya konstan, maka keputusan konsumen dalam

pengambilan kredit sepeda motor akan meningkat sebesar 0,487.

c) Koefisien $b_{2}=0,328$, artinya bahwa jika variabel komunikasi $\left(\mathrm{X}_{2}\right)$ naik satu satuan dan variabel lainnya konstan, maka keputusan konsumen dalam pengambilan kredit sepeda motor akan meningkat sebesar 0,487 .

Dari persamaan tersebut, diketahui bahwa semua korfisien regresi bernilai positif. Dengan demikian pelayanan dan komunikasi berpengaruh secara positif terhadap konsumen dalam pengambilan kredit sepeda motor.

\section{Hasil Pengujian Hipotesis}

\section{a. Hasil Uji Signifikansi Parsial (Uji t)}


Digunakan untuk menguji tingkat signifikansi variabel X terhadap Y secara parsial. Uji parsial (uji t) dilakukan dengan cara membandingkan nilai thitung dengan tabel. Nilai thitung diperooleh dari hasil pengolahan data dengan SPSS, sedangkan ttabel yang digunakan adalah nilai distribusi t pada $\alpha=0,05$ untuk derajat kebebasan $(\mathrm{df}=92-3=89)$ yaitu sebesar 1,662 .

\section{Tabel 2}

\section{Hasil Uji t}

\begin{tabular}{|c|c|c|c|c|c|c|}
\hline & & & \multirow{2}{*}{$\frac{i e}{e}$} & \multicolumn{3}{|c|}{ ients $\mathrm{s}^{\mathrm{a}}$} \\
\hline & & Unstandardi & & Standardized & $t$ & Sig. \\
\hline & & $B$ & Std. Error & Beta & & \\
\hline \multirow{3}{*}{1} & (Constant) & 3,784 & 1,271 & & 2,977 &, 004 \\
\hline & Pelayanan & ,487 & ,065 & 537 & 7,467 &, 000 \\
\hline & Komunikasi & 328 & .060 & 393 & 5,463 &, 000 \\
\hline
\end{tabular}

a. Dependent Variable: Keputusan konsumen

Berdasarkan hasil analisis pada Tabel diatas, maka nilaithitung dari tiap variabel X dibandingkan dengan nilai tabel sebagai berikut :

Variabel pelayanan $\left(\mathrm{X}_{1}\right)$, diperoleh nilai thitung $>$ ttabel yaitu 7,467 > 1,662dengan signifikansi 0,00 $<0,05$. Hasil tersebut menunjukkan bahwa pelayanan berpengaruh signifikan terhadap keputusan konsumen dalam pengambilan kredit sepeda motor pada PT. FIF Langga Payung. Dengan demikian hipotesis dapat diterima.

Variabel komunikasi $\left(\mathrm{X}_{2}\right)$, diperoleh nilai thitung $>$ ttabel yaitu 5,463> 1,662 dengan signifikansi $0,00<0,05$. Hasil tersebut menunjukkan bahwakomunikasi berpengaruh signifikan terhadap keputusan konsumen dalam pengambilan kredit sepeda motor pada

PT. FIF Langga Payung. Dengan demikian hipotesis dapat diterima.

\section{b. Hasil Uji Signifikansi Simultan (Uji F)}

Uji simultan (Uji F)digunakan untuk menguji pengaruh pelayanan $\left(\mathrm{X}_{1}\right)$ dan komunikasi $\left(\mathrm{X}_{2}\right)$ secara bersama-sama terhadap konsumen dalam pengambilan kredit sepeda motor pada PT. FIF Langga Payung(Y). Uji F dilakukan dengan membandingkan Fhitung dan Ftabel. 


\section{Tabel 3 Hasil Uji F}

ANOVA $^{\text {a }}$

\begin{tabular}{|c|c|c|c|c|c|c|}
\hline Model & & Sum of Squares & Df & Mean Square & $F$ & Sig. \\
\hline \multirow{3}{*}{1} & Regression & 136,629 & 2 & 68,315 & |78,727 & $000^{b}$ \\
\hline & Residual & 77,229 & 89 & ,868 & & \\
\hline & Total & 213,859 & 91 & & & \\
\hline
\end{tabular}

a. Dependent Variable: Keputusan konsumen

b. Predictors: (Constant), Komunikasi, Pelayanan

Berdasarkan Tabel diatas dari hasil pengolahan data menggunakan program SPSS 20.0 maka diperoleh nilai Fhitungsebesar 78,727 dengan signifikansi 0,00. Sedangkan nilai Ftabel yang digunakan adalah nilai distribusi $\mathrm{F}$ pada $\alpha=0,05$ dengan derajat kebebasan $\left(\mathrm{df}_{1}=3-1=2\right)$ dan $\left(\mathrm{df}_{2}=92-3=89\right)$ yaitu 3,10 .

Dengan demikian Fhitung $>$ Ftabel yaitu 78,727 82 lengan signifikansi $0,00<0,05$. Hal ini berarti bahwa pelayanan $\left(\mathrm{X}_{1}\right)$ dan komm...... $\left(\mathrm{X}_{2}\right)$ secara bersama-sama (simultan) berpengaruh signifikan terhadap keputusan konsumen dalam pengambilan kredit sepeda motor pada PT. FIF Langga Payung. Dengan demikian hipotesisdapat diterima.

c. Koefisien Determinasi $\left(R^{2}\right)$

Koefisien determinasi digunakan untuk mengetahui sejauhmanakemampuan variabel independen yaitu pelayanan $\left(\mathrm{X}_{1}\right)$ dan komunikasi $\left(\mathrm{X}_{2}\right)$ dalam menjelaskan variabel dependen (konsumen dalam pengambilan kredit sepeda motor).Besarnya Koefisien determinasi dapat dilihat pada Tabel 4 berikut ini :

\section{Tabel 4}

\section{Koefisien Determinasi}

Model Summary

\begin{tabular}{|l|l|l|l|l|}
\hline Model & $\mathrm{R}$ & $\mathrm{R}$ Square & $\begin{array}{l}\text { Adjusted } \mathrm{R} \\
\text { Square }\end{array}$ & $\begin{array}{l}\text { Std. Error of the } \\
\text { Estimate }\end{array}$ \\
\hline 1 &, $799^{\mathrm{a}}$ &, 639 &, 631 &, 93153 \\
\hline
\end{tabular}

a. Predictors: (Constant), Komunikasi, Pelayanan

Besarnya koefesien determinasi $\left(R^{2}\right)$ dapat dilihat pada kolom Adjusted $R$ Square sebesar 0,631. Hasil ini berartibahwa pelayanan $\left(\mathrm{X}_{1}\right)$ dan komunikasi $\left(\mathrm{X}_{2}\right)$ mampu mempengaruhi keputusan konsumen dalam pengambilan kredit sepeda motor pada PT. FIF Langga Payung sebesar $63,1 \%$.Sementara sisanya sebesar $36,9 \%$, loyalitas nasabah dipengaruhi faktor lain yang tidak dibahas dalam penelitian ini, misalnya : produk, citra perusahaankepuasan nasabah, dan lain sebagainya. 


\section{Pembahasan}

\section{a. Pengaruh Pelayanan Terhadap Keputusan Konsumen}

Hasil uji hipotesis secara parsial (Uji t) menunjukkan bahwa pelayanan ( $\mathrm{X}_{1}$ )berpengaruh positif dan signifikan terhadap keputusan konsumen dalam pengambilan

kredit sepeda motor pada PT. FIF Langga Payung. Hal ini dibuktikan dari nilai thitung $(7,467)>$ ttabel $(1,662)$ dengan taraf signifikansi $0,00<0,05$. Berdasarkan hasil analisis deskriptif menunjukkan bahwa kondisi penilaian responden terhadap kualitas pelayanan secara umum sudah baik.

Hal ini sejalan dengan penelitian Tan (2011) dalam penelitian yang berjudul Pengaruh Faktor Harga, Promosi, dan Pelayanan Terhadap Keputusan Konsumen Untuk Belanja di Alfamart Surabaya, dimana hasil penelitiannya menunjukkan bahwa bahwa pelayana berpengaruh terhadap keputusan konsumen untuk berbelanja di Alfamart Surabaya.

\section{b. Pengaruh Komunikasi Terhadap Keputusan Konsumen}

Hasil uji hipotesis secara parsial (Uji t) me 83 n bahwa komunikasi (X2) juga berpengaruh positif dan signifikan terhadap nasabah paua $г$ 1. Bank Perkreditan Rakyat (BPR) NBP 16 Rantauprapat. Hal ini dibuktikan dari nilai thitung $(5,463)>$ tabel $(1,662)$ dengan taraf signifikansi $0,00<0,05$. Berdasarkan hasil analisis deskriptif menunjukkan adanya komunikasi antara pihak FIF dengan konsumennya.

\section{c. Pengaruh Pelayanan dan Komunikasi Terhadap Keputusan Konsumen}

Hasil uji hipotesis secara simultan (uji F) menunjukkan bahwa pelayanan $\left(\mathrm{X}_{1}\right)$ dan komunikasi $\left(\mathrm{X}_{2}\right)$ secara bersama-sama berpengaruh positif dan signifikan terhadap keputusan konsumen dalam pengambilan kredit sepeda motor pada PT. FIF Langga Payung. Hal ini dibuktikan dari nilai Fhitung $>$ Ftabel yaitu 78,727 $>3,10$ dengan taraf signifikansi $0,00<0,05$.

Variabel pelayanan berpengaruh lebih dominan terhadap keputusan konsumen dalam pengambilan kredit sepeda motor pada PT. FIF Langga Payung. Hal ini dapat dilihat dari nilai koefisien regresi pelayanan $\left(\mathrm{X}_{1}\right)$ yaitu 0,487 lebih besar dari koefisien regresi komunikasi $\left(\mathrm{X}_{1}\right)$ yaitu 0,328 .

Berdasarkan uji determinasi diperoleh nilai Adjusted $R$ Square sebesar 0,631, yang berarti bahwa pelayanan dan komunikasi berpengaruh terhadap keputusan konsumen dalam pengambilan kredit sepeda motor pada PT. FIF Langga Payung sebesar 63,1\%. Nilai $R$ pada tabel hasi uji determinasi menunjukkan tingkat korelasi (hubungan) antara variabel bebas dan variabel terikat. Nilai $R$ sebesar $0,799(79,9 \%)$ menunjukkan adanya korelasi (hubungan) yang kuat antara pelayanan $\left(\mathrm{X}_{1}\right)$ dan komunikasi $\left(\mathrm{X}_{2}\right)$ terhadap keputusan konsumen dalam pengambilan kredit sepeda motor pada PT. FIF Langga Payung. 


\section{KESIMPULAN DAN SARAN}

\section{Kesimpulan}

Dari hasil analisis dan pembahasan yang telah diuraikan pada bab sebelumnya, maka dapat ditarik kesimpulan dari penelitian ini adalah :

Pelayanan secara parsial berpengaruh positif dan signifikan terhadap keputusan konsumen dalam pengambilan kredit sepeda motor pada PT. FIF Langga Payun.

Komunikasi secara parsial berpengaruh positif dan signifikan terhadap keputusan konsumen dalam pengambilan kredit sepeda motor pada PT. FIF Langga Payung.

Pelayanan dan komunikasi secara bersama-sama berpengaruh positif dan signifikan terhadap keputusan konsumen dalam pengambilan kredit sepeda motor pada PT. FIF Langga Payung.

Keputusan konsumen dalam pengambilan kredit sepeda motor pada PT. FIF Langga Payungmampu dijelaskan oleh pelayanan dan komunikasi sebesar $63,1 \%$, sedangkan sisanya

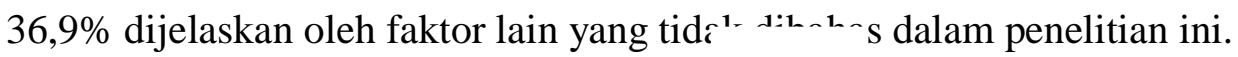

Berdasarkan kesimpulan diatas, maka peneıı memberikan saran sebagai berikut :

PT. FIF Langga Payungharus mampu meningkatkan kualitas pelayanan kepada konsumen dalam segala hal, misalnya mampu menerapkan penguasaan teknologi dalam melayani nasabah. Hal ini dapat dilakukan dengan cara membuat pelatihan terhadap karyawannya yang kurang mahir dibidang IT agar mampu melayani nasabahnya dengan baik dan memiliki kualitas pelayanan yang memuaskan sehingga membuat nasabah lebih loyal terhadap bank.

PT. FIF harus mampu membangun komunikasi yang baik dengan konsumen dan menjaga hubungan yang telah terbina selama ini agar dipertahankan. Membangun hubungan emosional dengan nasabah dapat dilakukan misalnya dengan membuat acara pertemuan dengan customer, mengadakan event-event tertentu yang melibatkan nasabah, seperti : acara jalan santai, acara natal bersama, dan lain sebagainya.

Bagi peneliti lainnya disarakan agar menambahkan variabel lain selain pelayanan dan komunikasi yang tentunya dapat mempengaruhi keputusan konsumen dalam pengambilan kredit sepeda motor pada PT. FIF Langga Payung agar lebih melengkapi penelitian ini karena masih ada variabel-variabel independen lain diluar penelitian ini yang mungkin bisa mempengaruhi keputusan konsumen. 


\section{DAFTAR PUSTAKA}

Akbar, Adam. 2012. "AnalisisPengaruh Citra Merek, Harga, danKualitasProdukTerhadapKeputusanPembelian Notebook Toshiba”. Jurnal, Jakarta :UniversitasGunadarma.

Arisutha, Damartaji. 2006. DimensiKualitasPelayanan. Jakarta : PT. GramediaPustaka.

Daft L, Richard. 2007. Manajemen. Jakarta :Erlangga.

Ghozali,Imam. 2009. AplikasiAnalisis Multivariate dengan Program SPSS. Semarang :BadanPenerbitUniversitasDiponegoro.

Kertajaya, Hermawan. 2009. PerjalananPemikiranKonsepPemasaran. Jakarta:

PT.GeloraAksaraPratama.

Kotler, Philip dan Gary Armstrong. 2008. Prinsip-PrinsipPemasaran, Jilid 1 Edisi 12, Erlangga, Jakarta.

Kotler, Philip. 2009. ManajemenPemasaran. Jakarta :Erlangga.

Kuncoro, Mudrajad. 2009. MetodeRisetuntukBisnis\&Ekonomi (Edisi 3).Jakarta :Erlangga.

Margaretha, Farah. 2007. KualitasPelayanan :TeoridanPraktik. Jakarta: PT.

GramediaPustaka.

Martul,Shadiqqin. 2006. Implementasi Dimensi Kualitas Pelayanan. Jakarta: PT. Gramedia Pustaka.

Nurlisa. 2011. "Pengaruh Harga, Kualitas Produk, Dan Citra MerekTerhadapKeputusanPembelianKecapManisMerekBango (Studi Kasus Pada Ibu Rumah Tangga Di Komplek Villa Mutiara Johor Ii Dan Taman Johor Mas)”. Jurnal, Universitas Sumatra Utara.

Purwanto, Djoko. 2006. KomunikasiBisnis. EdisiRevisi. Jakarta :BumiAksara. . 2011. KomunikasiBisnis. EdisiKedua. Jakarta :Erlangga.

Setiadi, Nugroho J. 2010. PerilakuKonsumen. EdisiRevisi. Jakarta :Kenca 